\title{
Evaluation of the Adsorption Efficiency of Glycine-, Iminodiacetic Acid -, and Amino Propyl-Functionalized Silica Nanoparticles for the Removal of Potentially Toxic Elements from Contaminated Water Solution
}

\author{
Abdullah M. Alswieleh $\left({ }^{1},{ }^{1}\right.$ Hajar Y. Albahar, ${ }^{1}$ Amal M. Alfawaz, ${ }^{1}$ Abdulilah S. Alsilme, \\ Abeer M. Beagan (D), Ali M. Alsalme ${ }^{1},{ }^{1}$ Mohammed S. Almeataq, ${ }^{2}$ Ahmed Alshahrani, \\ and Khalid M. Alotaibi ${ }^{1}{ }^{1}$ \\ ${ }^{1}$ Department of Chemistry, College of Science, King Saud University, PO Box 2455, Riyadh 11451, Saudi Arabia \\ ${ }^{2}$ King Abdulaziz City for Science and Technology, Riyadh, Saudi Arabia \\ Correspondence should be addressed to Abdullah M. Alswieleh; aswieleh@ksu.edu.sa and Khalid M. Alotaibi; khalid.m@ksu.edu.sa
} Received 3 October 2020; Revised 28 November 2020; Accepted 15 December 2020; Published 4 January 2021

Academic Editor: Hiromasa Nishikiori

Copyright (C) 2021 Abdullah M. Alswieleh et al. This is an open access article distributed under the Creative Commons Attribution License, which permits unrestricted use, distribution, and reproduction in any medium, provided the original work is properly cited.

\begin{abstract}
In present work, mesoporous silica nanoparticles (MSNs) were prepared with a surface area of $1048 \mathrm{~m}^{2} \mathrm{~g}^{-1}$ and a large pore size of ca. $6 \mathrm{~nm}$, using Stöber process in the presence of expanding reagent ( $n$-hexane). The surface of MSNs was modified with three different functional groups (amine, iminodiacetic acid, and glycine) and characterized by a variety of physicochemical techniques. The adsorption studies were carried out at different $\mathrm{pH}$ values in two extraction systems. In batch method, the maximum adsorption efficiency of heavy metals was measured to be $95 \%$ for all fabricated MSNs at $\mathrm{pH} 9$. At $\mathrm{pH} 3$, the adsorption efficiency of $\mathrm{Pb}$ and $\mathrm{Cu}$ was observed to be affected by the carboxylic moiety involved in the functional group. As the number of carboxylic moieties increase, the removal efficiency of $\mathrm{Pb}$ and $\mathrm{Cu}$ ions increased by two folds. The results demonstrated the selectivity of IDA-MSNs for the removal of $\mathrm{Pb}$ and $\mathrm{Cu}$ ions, even though the multielements are present in an aqueous solution. On the other hand, the incorporation of MSNs into the polymeric membrane showed high water permeability $\left(9.96 \pm 3 \mathrm{~L} / \mathrm{m}^{2}\right.$.h.bar), and $98 \%$ rejection was achieved at $\mathrm{pH} 7$ for $\mathrm{Cu}^{+2}$ and $\mathrm{Pb}^{+2}$ ions.
\end{abstract}

\section{Introduction}

The 2018 edition of the UN World Water Development Report stated that more than 5 billion people could experience severe water scarcity by 2050 . This is due to the increased demand for water, limited water resources, and increasing pollution of water, which is caused by dramatic population and economic growth [1]. Emerging contaminants such as heavy metals (e.g., $\mathrm{Hg}$, $\mathrm{As}, \mathrm{Pb}$, and $\mathrm{Cd}$ ) in the treated wastewater is of concern for the environment and human health. Even the presence of trace levels of heavy metals in the treated wastewater may have long-term health impacts. As a consequence, considerable attention has been paid on the development of new nanosystems for the fast, selective, and efficient removal of hazardous heavy metal ions from water [2-4].

Mesoporous silica nanoparticles (MSNs) have emerged as one of the most promising technologies for water remediation which can be used in the form of adsorbents $[5,6]$, hosts [7, 8], and sensors [9]. Indeed, MSNs become apparent as a promising water treatment technique due to their favourable chemical properties, thermal stability, and biocompatibility [10-12]. The surface modification of silica nanoparticle with a suitable functional group could enhance the efficiency, sensitivity, and selectivity of the material towards hazardous heavy metal ions [13-15]. For example, thiol terminated silica surfaces showed an improvement in adsorption of $\mathrm{Ag}, \mathrm{Hg}, \mathrm{Cu}, \mathrm{Zn}$, and $\mathrm{Ni}$ ions from aqueous 
solution [16], whereas amine-terminated surfaces improved sorption properties for $\mathrm{Cr}, \mathrm{Pb}$, and $\mathrm{Cd}$ ions $[17,18]$. Theoretical modelling of binding heavy metals (i.e., $\mathrm{Cd}, \mathrm{Pb}, \mathrm{Cu}$, and $\mathrm{Zn}$ ) on surface modified with thiol, amino, or carboxyl functionalities demonstrated that the key features which determine the improved performance of the functionalized materials were as follows: (a) high metal loading capacities due to the ligands and (b) strong binding affinities for the selected metal ions due to the nature of the functional groups [19]. Gibson and coworkers reported the synthesis of silica nanoparticles with a broad pore-size distribution [20]. The researchers studied the effect of adsorbent pore size distribution on the rate of $\mathrm{Cr}$ (VI) ions uptake. The results showed that the adsorption behaviour of $\mathrm{Cr}$ (VI) ions was affected by the size of the particles [21]. Gupta et al. reported the synthesis of guanine functionalized MSNs for removal of toxic metal ions from aqueous medium [22]. The fabricated MSNs demonstrated proficient removal capacities of toxic metal ions $\left(\mathrm{Hg}^{2+}, \mathrm{Cd}^{2+}\right.$, and $\left.\mathrm{Pb}^{2+}\right)$ from aqueous solution. Carbon quantum dots (CQDs) embedded in MSNs were prepared via hydrothermal approach [23]. It was found that MSNs/CQDs was high selectivity of $\mathrm{Hg}^{2+}$. Li et al. reported the synthesis of amino-functional mesoporous silica spheres by a one-step method, with large particle size ( $>1 \mathrm{~mm}$ ) [24]. The material exhibited an excellent $\mathrm{Pb}^{2+}$ adsorption in both dynamic and static experiments. Sodium dodecyl sulfate(SDS-) functionalized MSNs were prepared as adsorbent for removing toxic metal from aqueous solution [25]. The adsorption capacity was observed to be dependent on the metal ion and the $\mathrm{pH}$ of solution. Mesoporous silica was functionalized with triethylenetetramine (TETA) to be used for removal $\mathrm{Cu}^{2+}$ and $\mathrm{Zn}^{2+}$ metal ions from aqueous solutions [26]. Magnetic mesoporous nanoparticles were modified with EDTA and used to remove Cr(III) from water with high salinity [27]. The nanomaterials illustrate high adsorption capacity for $\mathrm{Cr}$ (III), with maximum adsorption amount of $30.59 \mathrm{mg} . \mathrm{L}^{-1}$ in acidic media.

The incorporation of nanoparticles into the polymeric thin-film composite membranes could enhance the physicochemical properties of the membranes: including mechanical stability, thermal resistance, and hydrophilicity as well as their permselectivity [28-31]. Importantly, the modification of the MSNs with hydrophilic groups could be beneficial for improving fouling resistance and permeability of the membranes $[28,32]$. Shah et al. prepared aminofunctionalized-multiwalled carbon nanotube/polysulfone composite membranes, such membranes were evaluated for the removal of heavy metals, showing maximum adsorption of $78.2 \%$ and $94.2 \%$ for cadmium and chromium, respectively [33]. Zhu et al. synthesised hollow fiber membranes by grafting polyamidoamine (PAMAM) on the interfacially polymerized layer of polyethersulfone (PES) membranes for removal of $\mathrm{Pb}(\mathrm{II}), \mathrm{Cd}(\mathrm{II})$, and $\mathrm{Cu}(\mathrm{II})$ [34]. The membrane showed an ion rejection of more than $95 \%$ and a water permeability flux of $3.6 \mathrm{~L} \mathrm{~m}^{-}{ }^{2} \mathrm{~h}^{-1} \mathrm{bar}^{-1}$. Zhang et al. reported the removal of $\mathrm{Pb}(\mathrm{II}), \mathrm{Zn}(\mathrm{II})$, and $\mathrm{Ni}(\mathrm{II})$ using graphene oxide (GO) framework layer deposited on a modified Torlon hollow fibre [35]. The GO/Torlons composite membrane has rejections higher than $95 \%$ towards the target heavy metals with water permeability flux of $4.7 \mathrm{~L} \mathrm{~m}^{-2} \mathrm{~h}^{-1} \mathrm{bar}^{-1}$. However, the high rejection percentage of ions comes with a cost of having low permeability flux. High throughput and significant rejection could be achieved by the incorporation of functionalized mesoporous silica materials into polymeric membranes.

The implementation of these objectives has largely been attempted in this study through the use of nanocomposite functionalized membranes utilizing surface-modified MSNs for the removal of heavy metal ions from aqueous solutions. As far as we know, very little works have been reported on the surface modification of silica nanoparticle with two functional groups (amine and carboxylic acid groups). The aim of this work is the fabrication of high surface area silica nanoparticles functionalized with amine and carboxylic acid groups and the use of such materials for hazardous heavy metal ions adsorptions. Herein, MSNs functionalized with amine, iminodiacetic acid, and glycine were prepared and characterized by a variety of physicochemical techniques, including FT-IR, elemental analysis, TGA, SEM, TEM, and BET analysis. Furthermore, the adsorption studies were carried out in batch mode at different $\mathrm{pH}$ values with nanoparticles being in the colloidal form, as well as the nanoparticles incorporated into the polymeric membrane. The membrane was then characterized in terms of permeability and the effect of solution $\mathrm{pH}$ on the removal of heavy metals.

\section{Materials and Methods}

2.1. Materials. Deionized water was obtained using an Elga Pure Nanopore 18.2 M $\Omega$ system. 3-Aminopropyltriethoxysilane (APTES, >98\%), ethanol (99.8\%, HPLC grade), Ncetyltrimethylammonium bromide (CTAB, 98\%), toluene (analytical grade) tetraethylorthosilicate (TEOS, 98\%), iminodiacetic acid (IDA, 95\%), glycine (98.5\%), $n$-hexane (HPLC grade), methanol (99.8\% HPLC grade), and ammonium hydroxide (28 wt \%) were purchased from Sigma-Aldrich. Hydrochloric acid $(\mathrm{HCl})$ and dimethyl sulfoxide (DMSO) were obtained from Fisher Scientific. All the chemicals were used as received.

\subsection{Mesoporous Silica Preparations and Functionalization}

\subsubsection{Synthesis of Mesoporous Silica Nanoparticles (MSNs).} Typically, $1 \mathrm{~g}$ of CTAB was dissolved in a solution of $160 \mathrm{~mL}$ of deionized water and $1 \mathrm{~mL}$ of concentrated ammonia water $(28 \mathrm{wt} \%)$ under stirring. A mixture solution of $n$ -hexane $(20 \mathrm{~mL})$ and TEOS $(5 \mathrm{~mL})$ was added into the solution within $30 \mathrm{~min}$ under continuous stirring at $35^{\circ} \mathrm{C}$. After stirring for $12 \mathrm{~h}$, the product was collected by centrifugation and washed with deionized water and ethanol. The collected solid sample was dried in an oven at $100^{\circ} \mathrm{C}$ for $2 \mathrm{~h}$ [24].

Then, the sample was submitted to solvent extraction treatment to remove CTAB templates by redispersing $1.5 \mathrm{~g}$ of the sample in methanol $(160 \mathrm{~mL})$, to which a concentrated aqueous solution of $\mathrm{HCl}(12 \mathrm{M}, 9 \mathrm{~mL})$ was added, and the mixture was heated under reflux for $24 \mathrm{~h}$. The solvent extraction was repeated 2 times, and the sample was collected by centrifugation, followed with washing with ethanol 6 times, and finally vacuum dried overnight. 
2.2.2. Synthesis of 3-Aminopropyl-Functionalized MSNs (AP$M S N s$ ). Amino functionalized silica surface was prepared by suspending the obtained nanoparticles $(1.5 \mathrm{~g})$ in a solution of APTES $(2.5 \mathrm{mmol})$ in dry toluene $(50.0 \mathrm{~mL})$, and the resulting mixture was heated under reflux $\left(130^{\circ} \mathrm{C}\right)$ for $24 \mathrm{~h}$ (Scheme 1(a)). The nanoparticles were collected by centrifugation, washed twice with toluene and five times with ethanol, and dried under vacuum.

2.2.3. Synthesis of (3-Glycidyloxypropyl)-Functionalized MSNs (Epo-MSNs). (3-Glycidyloxypropyl)-coated mesoporous silica surface was performed by suspending the obtained nanoparticles $(1.5 \mathrm{~g})$ in a solution of (3-glycidyloxypropyl) trimethoxysilane $(2.5 \mathrm{mmol})$ in dry toluene $(50.0 \mathrm{~mL})$, and the resulting mixture was heated under reflux for $24 \mathrm{~h}$. The nanoparticles were collected by centrifugation, washed twice with toluene and five times with ethanol, and dried under vacuum.

2.2.4. Preparation of Glycine-Modified MSNs (Gly-MSNs). (3Glycidyloxypropyl)-coated MSNs ( $1 \mathrm{~g}$ ) were added to a flask containing $20 \mathrm{~mL} \mathrm{DMSO}$ and kept at $60^{\circ} \mathrm{C}$ for $1 \mathrm{~h}$ with stirring. An aqueous solution $(10 \mathrm{~mL})$ containing glycine $(3 \mathrm{~g})$ was added to the mixture stirred for $48 \mathrm{~h}$ at $85^{\circ} \mathrm{C}$ (Scheme 1(b)). Gly-MSNs were collected by centrifugation and washed thoroughly with deionized water and ethanol, then dried in a vacuum.

2.2.5. Preparation of IDA-Modified MSNs (IDA-MSNs). Before the reaction, iminodiacetic acid (IDA) is neutralized with $\mathrm{KOH}$ solution to keep carboxylic acid from reacting with epoxy ring of MSNs surface. Dipotassium salt of IDA solution $(1 \mathrm{M}, 100 \mathrm{~mL})$ was added slowly to a water suspension $(10.0 \mathrm{~mL})$ of (3-glycidyloxypropyl)-coated MSNs $(2.0 \mathrm{~g})$. The mixture was kept at $65-70^{\circ} \mathrm{C}$ overnight under powerful stirring (Scheme 1(c)). The resulting material was centrifuged, washed extensively with water and ethanol, and dried under vacuum.

2.2.6. Preparation of Membranes. Three dispersions in this study were prepared using chitosan solution $(0.5 \% \mathrm{w} / \mathrm{v})$, which contained nanopartials (amine, glycine, and IDA) with a concentration of $0.1 \%(w / v)$. In a typical experiment, $15 \mathrm{mg}$ of these nanopartials were dispersed in $15 \mathrm{~mL}$ of surfactant (Milli-Q ${ }^{\circledR}$ water and chitosan) using ultrasonics with a probe diameter of $10 \mathrm{~mm}$ for $10 \mathrm{~min}$, which required time for complete dispersion of each nanopartials (amine, glycine, and IDA) through solutions. The vial was located inside an ice/water bath to keep a constant temperature during sonication process. The resulting solutions were then applied to a flat membrane $(12 \mathrm{~cm} \mathrm{X} 12 \mathrm{~cm})$ of polysulfone (support layer) and dried at $21^{\circ} \mathrm{C}$ for $24 \mathrm{~h}$.

2.3. Adsorption Experiments. The general procedure for the extraction of the selected elements from solution can be summarised as follows. Approximately $25 \mathrm{mg}$ samples of AP-MSNs, IDA-MSNs, or Gly-MSNs were suspended in $25 \mathrm{~mL}$ solutions containing $10 \mathrm{ppm}$ of the selected elements (i.e., $\mathrm{Cu}, \mathrm{Cd}, \mathrm{Co}, \mathrm{Cr}, \mathrm{Pb}$, and $\mathrm{Zn}$ ) at $\mathrm{pH}$ between 3 and 9. Solutions were stirred for approximately $2 \mathrm{~h}$ at room tem- perature and then filtered. The supernatants were analyzed using ICP/OES.

2.3.1. Permeability Studies. The permeability of three coating membranes (Gly-MSN, IDA-MSN, and AP-MSN) towards water was investigated using the cross-flow filtration system outlined in Scheme 2. The coating membrane was first located on a porous stainless steel that was used as support to the membrane and the active filtration area of the filtration cell was $40 \mathrm{~cm}^{2}$. Different pressures were applied to force water through the coating membrane in order to obtain a flux across the coating membrane. For the flux of water, the volume $(\mathrm{mL})$ of water passing the coating membrane at each applied pressure was measured for $6 \mathrm{~min}$ by the cross-flow meter linked to a computer.

2.3.2. Heavy Metals Rejection Study. The performance of the synthesised membranes (Gly-MSN, IDA-MSN, and APMSN) was investigated using a cross-flow filtration system (Scheme 2) at different applied pressure and at ca. $20 \pm 2^{\circ} \mathrm{C}$ in order to evaluate the heavy metals ions rejection. The feed solution was prepared with Milli-Q water and $10 \mathrm{ppm}$ concentration a mixture of heavy metals ions $\left(\mathrm{Cu}^{+2}, \mathrm{Ni}^{+2}, \mathrm{~Pb}^{+2}\right.$, $\mathrm{Cd}^{+2}$, and $\left.\mathrm{Co}^{+2}\right)$. The $\mathrm{pH}$ value $(3,7$ and 10$)$ of the feed solution was adjusted by $\mathrm{HCl}$ and $\mathrm{NaOH}$, and all the permeate volumes through three membranes were taken after $30 \mathrm{~min}$. The concentrations in the samples at the feed solution and the permeate volume were measured by an inductively coupled plasma/optical emission spectroscopy, ICP/OES (Varian 720-ES) using equation (1)

$$
R=\left(\frac{1-C_{p}}{C_{F}}\right) * 100
$$

where $C_{p}$ and $C_{f}$ are the concentration of metal ions for the permeate and feed solution, respectively.

2.4. Measurement and Characterization. Surface area analysis: the surface area of silica nanoparticulate materials used in this study was measured using nitrogen physisorption isotherms on a Micromeritics Gemini 2375 volumetric analyzer. Each sample was degassed prior to analysis for $6 \mathrm{~h}$ at $150^{\circ} \mathrm{C}$. The Brunauer-Emmett-Teller (BET) surface areas were calculated using experimental points at a relative pressure $\left(\mathrm{P} / \mathrm{P}^{\circ}\right)$ of $0.05-0.25$. The total pore volume was calculated from the $\mathrm{N}_{2}$ amount adsorbed at the $\mathrm{P} / \mathrm{P}^{\circ}$ of 0.99 for each sample, and the average pore size distribution of the materials was calculated using the Barrett-Joyner-Halenda (BJH) model. FTIR spectroscopy: infrared spectra of all samples were obtained in $\mathrm{KBr}$ pellets in the $4000-400 \mathrm{~cm}^{-1}$ region with a resolution of $4 \mathrm{~cm}^{-1}$, using a Thermo Scientific Nicolet iS10. Elemental analysis (EA): elemental analysis was carried out using a Perkin Elmer Series II-2400 analyzer. Scanning electron microscopy (SEM): SEM images were collected using JEOL JSM-6380 LA scanning electron microscope. The dried samples were directly used for the observation without any treatment. Transmission electron microscopy (TEM): a drop of dilute sample suspension in ethanol was placed on a copper grid with a thin polymer coating and dried at room 


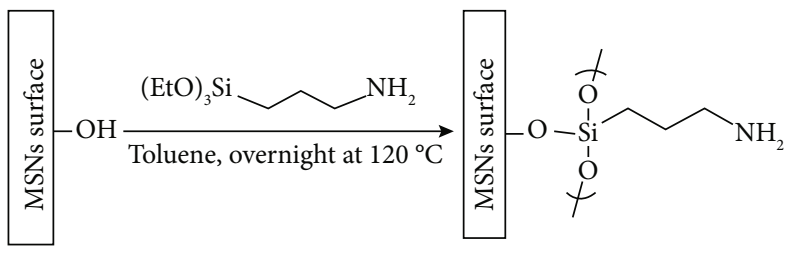

(a)
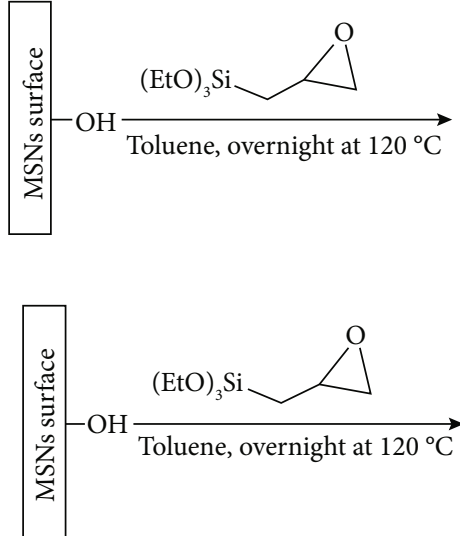<smiles>CO[Si](CC1CO1)(OC#CC1CC1)OC(C)C</smiles>

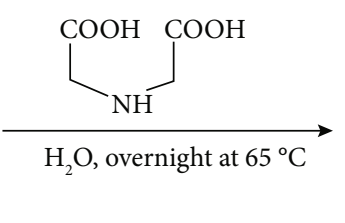

(c)<smiles>CO[Si](CC(O)NCC(=O)O)(OC#CC1CC1)OC(C)C</smiles>

DMSO and $\mathrm{H}_{2} \mathrm{O}$, overnight at $85^{\circ} \mathrm{C}$<smiles>NCC(=O)O</smiles>

MSO and $\mathrm{H}_{2} \mathrm{O}$, overnight at $85^{\circ} \mathrm{C}$<smiles>CO[Si](CC(O)CN(CC(=O)O)CC(=O)O)(OC#CC1CC1)OC(C)C</smiles>

Scheme 1: Surface modification of mesoporous silica nanoparticles (MSNs) with: (a) amine, (b) glycine, and (c) iminodiacetic acid (IDA).

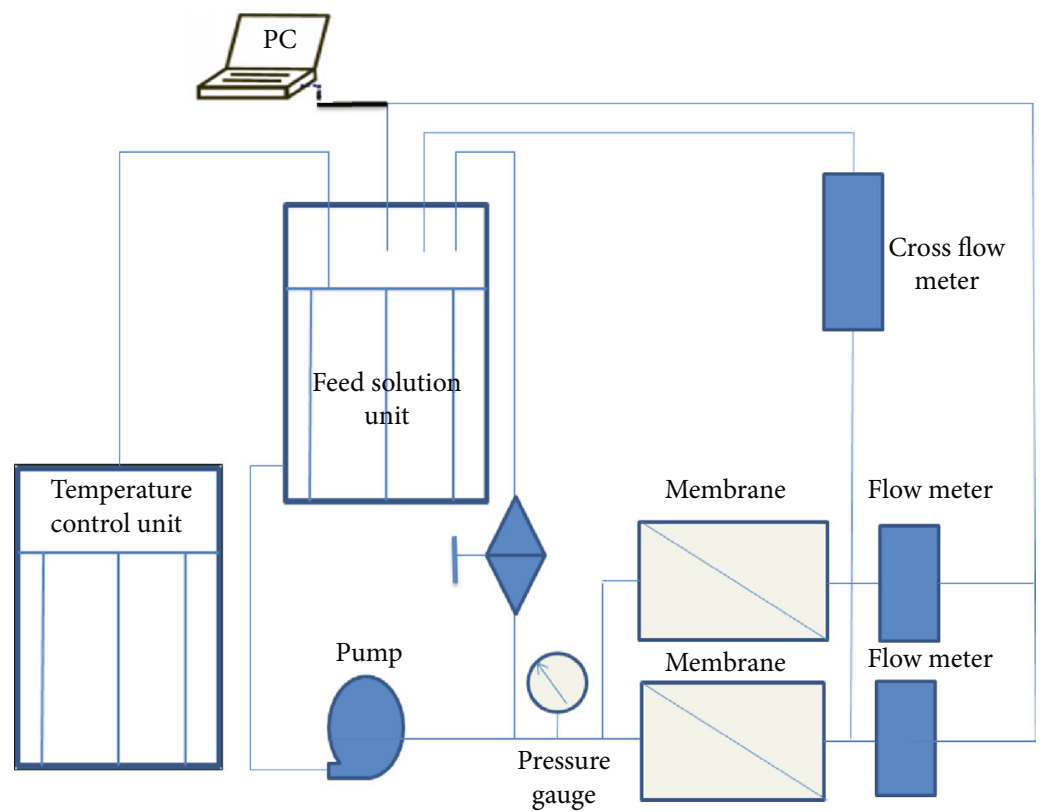

Scheme 2: Schematic illustration of the cross-flow system.

temperature prior to the measurement. A JEOL JEM-1230 transmission electron microscope was used for TEM imaging. Thermogravimetric analysis (TGA): TGA analyses were carried out on a SII TGA 6300 instrument with a heating rate of $10^{\circ} \mathrm{C} / \mathrm{min}$ under $\mathrm{N}_{2}$. ICP analysis: the elemental compositions of the supernatants were determined by inductively coupled plasma/optical emission spectroscopy, ICP/OES (Varian 720-ES). For the supernatant samples, $0.4 \mathrm{~mL}$ of highly concentrated nitric acid was added, and the total vol- ume was adjusted to $10 \mathrm{~mL}$ with $\mathrm{DI}$ water prior to ICP/OES analysis.

\section{Results and Discussion}

3.1. Characterization of Materials. The morphology, means diameter, and size distribution of the silica nanoparticles were characterized by scanning electron microscopy (SEM) and transmission electron microscopy (TEM). SEM 


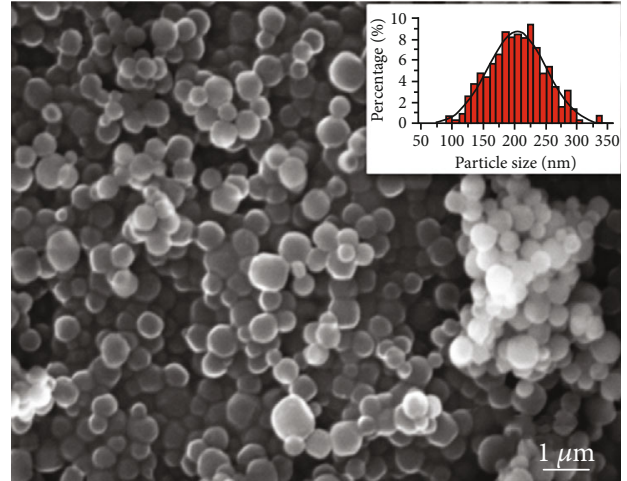

(a)

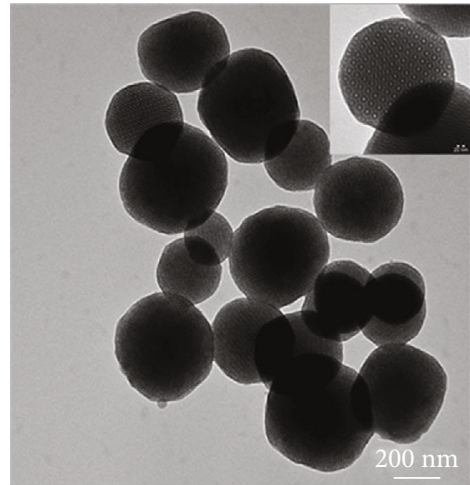

(b)

FIGURE 1: (a) SEM image of fabricated silica nanoparticles. (b) TEM image of mesoporous silica nanoparticles.

characterization indicates that the obtained MSNs sample consists of nanospheres. The particle size distribution was estimated using the Image $J$ software by analysing the SEM image. The majority of MSNs ranged between 150 and $280 \mathrm{~nm}$. The average particle size was calculated to be $200 \mathrm{~nm}$ for all prepared nanoparticles, as shown in Figure 1(a). TEM observation (Figure 1(b)) reveals that the obtained mesoporous silica nanospheres are highly dispersed without aggregation and have regular morphology with a diameter ranging from 150 to $300 \mathrm{~nm}$, agreeing well with the SEM results. The highly ordered arrays of uniform spherical mesopores can be clearly seen in the TEM images. The mesopores size was estimated from the TEM image to be ca. $6 \mathrm{~nm}$, which is larger than those of typical mesoporous silica nanoparticles, due to the pore expanding effect of nonpolar $n$-hexane $[15,36]$.

All samples of bare MSNs, AP-MSNs, Gly-MSNs, and IDA-MSNs were characterized using BET. The physicochemical properties of the samples were summarized in Table 1 . As expected, reductions in surface area and pore volume were observed after the modification of the surfaces due to introducing the functional groups into the surface and the pores of MSNs. In Figure 2, the $\mathrm{N}_{2}$ sorption isotherms for all samples were found to be Type IV, confirming their mesoporous nature. A slightly different capillary condensation steps were noted at higher relative pressures for AP-MSNs, GlyMSNs, and IDA-MSNs compared with nonmodified surfaces. The hysteresis loop was broader for MSNs, compared to the modified MSNs suggesting that the pore shapes and sizes of modified materials had been changed. All samples have a pore size of about $4-6 \mathrm{~nm}$ with a relatively narrow pore size distribution (Figure 3). The pore size of MSNs was found ca. $6 \mathrm{~nm}$, as estimated from the TEM image. AP-MSNs sample had well-defined narrow pore size ranges and similar average pore size to MSNs, whereas a reduction in the average pore size of Gly-MSNs and IDA-MSNs.

FTIR characterization shows that wide bands at 1240$1030 \mathrm{~cm}^{-1}$ were attributed to the asymmetric stretching of siloxane groups ( $\mathrm{Si}-\mathrm{O}-\mathrm{Si}$ ) bands of the condensed silica network. Peak at $\sim 1630 \mathrm{~cm}^{-1}$ was ascribed to the bending vibration of water. Peak at $\sim 806 \mathrm{~cm}^{-1}$ was assigned to stretching vibration of $\mathrm{Si}-\mathrm{O}$. These features were found in all samples.
TABLe 1: Physiochemical data and water permeability obtained for the bare MSNs, AP-MSNs, Gly-MSNs, and IDA-MSNs samples.

\begin{tabular}{lcc}
\hline Material & BET surface area $\left(\mathrm{m}^{2} \cdot \mathrm{g}^{-1}\right)$ & Pore volume $\left(\mathrm{cm}^{3} \cdot \mathrm{g}^{-1}\right)$ \\
\hline Bare MSNs & 1048 & 1.51 \\
AP-MSNs & 681 & 1.00 \\
Gly-MSNs & 570 & 0.95 \\
IDA-MSNs & 783 & 0.98 \\
\hline
\end{tabular}

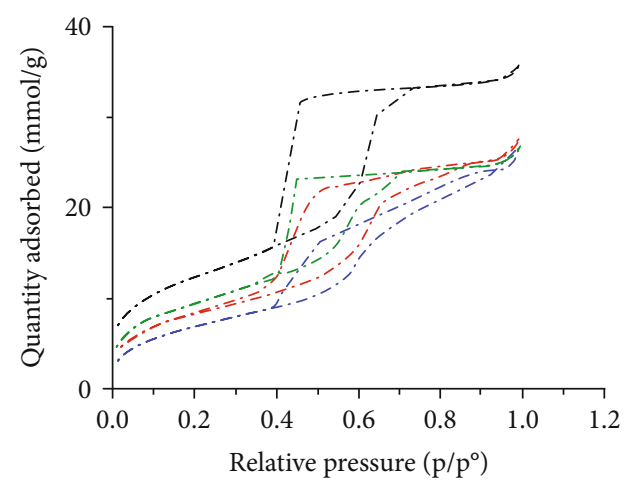

$\cdot-\cdot-$ MSNs (adsorption)

-. MSNs (desorption)

-. - MSNs-AP (adsorption)

-.- MSNs-AP (desorption)

-.-- MSNs-Gly (adsorption)

-..- MSNs-Gly (desorption)

-. - MSNs-IDA (adsorption)

$\cdot-\cdot-$ MSNs-IDA (desorption)

FIgURe 2: Nitrogen adsorption isotherms of the MSNs, AP-MSNs, Gly-MSNs, and IDA-MSNs samples.

Peaks at $\sim 1489 \mathrm{~cm}^{-1}$ and $\sim 2928 \mathrm{~cm}^{-1}$ were attributed to C-H as $-\mathrm{CH}_{2}$ - in template (CTAB). After extraction treatment, the peaks at $\sim 1489 \mathrm{~cm}^{-1}$ and $2928 \mathrm{~cm}^{-1}$ were disappeared, indicating that the $\mathrm{CTAB}$ template was completely removed. When comparing MSNs spectrum with AP-MSNs spectrum, new peaks at ca. $694 \mathrm{~cm}^{-1}, 1489 \mathrm{~cm}^{-1}, 1630 \mathrm{~cm}^{-1}$, and $1565 \mathrm{~cm}^{-1}$ appeared after APTES modification. The absorption peaks for AP-MSNs at $\sim 694 \mathrm{~cm}^{-1}$ were ascribed to N$\mathrm{H}$ as bending vibration in $-\mathrm{NH}_{2}$. Peaks at $\sim 1630 \mathrm{~cm}^{-1}$ and 


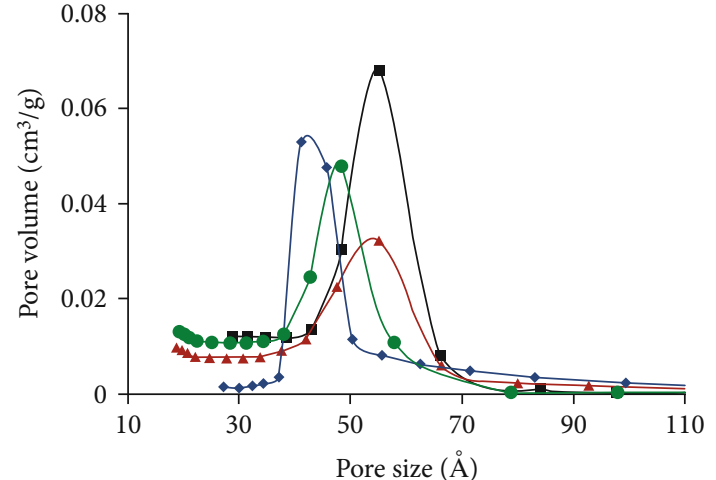

Figure 3: BET pore size distribution patterns of the MSNs, APMSNs, Gly-MSNs, and IDA-MSNs samples.

$\sim 1565 \mathrm{~cm}^{-1}$ were ascribed to $\mathrm{N}-\mathrm{H}$ as stretch vibration in $-\mathrm{NH}_{2}$. Peaks at $\sim 1489 \mathrm{~cm}^{-1}$ were ascribed to $\mathrm{C}-\mathrm{H}$ as $-\mathrm{CH}_{2}-$ in APTES. Peaks around $2928 \mathrm{~cm}^{-1}$ ascribed to $\mathrm{C}-\mathrm{H}$ as stretch vibration in $-\mathrm{CH}_{2}-$ appeared after modification. Peak appeared at $\sim 1489 \mathrm{~cm}^{-1}$, corresponding to $\mathrm{C}-\mathrm{H}$ as $-\mathrm{CH}_{2}-$ in the epoxy-functionalized MSNs. There is also a peak at $\sim 2928 \mathrm{~cm}^{-1}$, as a C-H as stretch vibration in $-\mathrm{CH}_{2}$ - was appeared after modification. After the reaction with glycine, and iminodiacetic acid (IDA), peaks appeared at $\sim 1470 \mathrm{~cm}^{-}$ ${ }^{1}$ assigned to $\mathrm{N}-\mathrm{H}$ stretch and a weak band at $693 \mathrm{~cm}^{-1}$. Peaks at $\sim 1720 \mathrm{~cm}^{-1}$ appeared, assigned to carbonyl groups, providing an evidence of successful reaction between the epoxy group and amino groups in glycine and IDA, as these peaks were absent in the epoxy-MSNs spectrum. Peaks around $1489 \mathrm{~cm}^{-1}$ and $2928 \mathrm{~cm}^{-1}$ ascribed to C-H was enhanced after modification, further indicating the successful reactions with epoxy surface.

Elemental analysis was used to estimate the amount of molecules $\left(\mathrm{L}_{\mathrm{o}}\right)$ attached to the surfaces of the AP-MSNs, Epo-MSNs, Gly-MSNs, and IDA-MSNs samples using the measured percentage of nitrogen. See the following equation:

$$
\text { Lo }=\frac{\% \mathrm{~N}}{\text { nitrogen atomic weight }} \times 10
$$

The Lo values were calculated and demonstrated in Table 2.

The successful surface modifications of the materials were evaluated by thermogravimetric analysis (TGA), when heating in a $\mathrm{N}_{2}$ atmosphere to $1000^{\circ} \mathrm{C}$ (Figure 4). After surface modification with APTES and (3-glycidyloxypropyl) trimethoxysilane, ca. $15 \mathrm{wt} \%$ of weight loss was observed. The TGA result revealed that the content of $-\mathrm{NH}_{2}$ and epoxy groups in the surface of MSNs were ca. $0.68 \mathrm{mmol} / \mathrm{g}$. Also, the TGA result showed that the content of glycine in the Gly-MSNs was $0.53 \mathrm{mmol} / \mathrm{g}$, whereas the content of IDA in the IDA-MSNs was $0.046 \mathrm{mmol} / \mathrm{g}$. These results suggest that ca. $80 \%$ of epoxy groups on the surface was reacted glycine, and ca. $70 \%$ of epoxy groups on the surface was reacted IDA.

3.2. Adsorption Studies. One of the most important factors in the adsorption process that influence the silica adsorbent-
TABle 2: Elemental analysis data obtained for the modified mesoporous silica.

\begin{tabular}{lcccc}
\hline Material & $\% \mathrm{C}$ & $\% \mathrm{H}$ & $\% \mathrm{~N}$ & $\mathrm{~L}_{\mathrm{o}}(\mathrm{mmol} / \mathrm{g})^{\mathrm{a}}$ \\
\hline AP-MSNs & 6.38 & 1.87 & 1.62 & 1.16 \\
Epo-MSNs & 8.41 & 2.14 & - & - \\
Gly-MSNs & 8.29 & 2.33 & 1.18 & 0.84 \\
IDA-MSNs & 9.46 & 2.51 & 1.37 & 0.98 \\
\hline
\end{tabular}

${ }^{a}$ Functionalization degree (in millimoles of ligand per gram of functionalized silica).

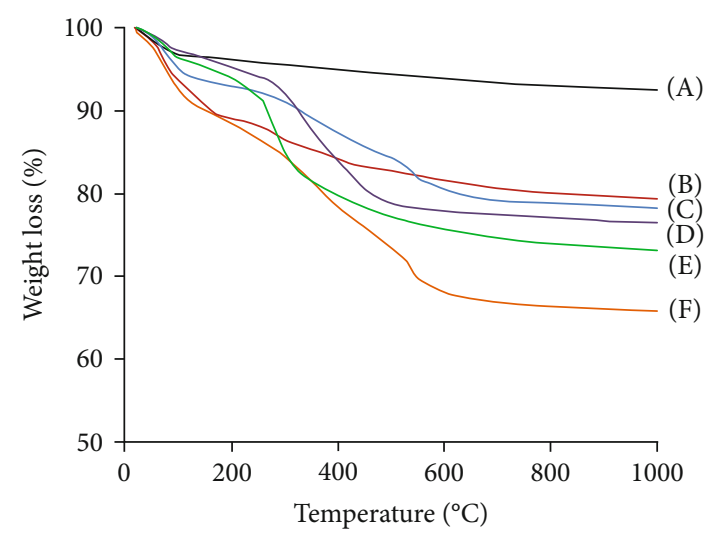

Figure 4: TGA analysis of (a) MSNs, (b) AP-MSNs, (c) EpoxyMSNs, (d) Gly-MSNs, (e) IDA-MSNs, and (f) MSNs as made samples.

adsorbate interactions is the $\mathrm{pH}$ of the solution, due to its ability to change the ionic state of the analytes as well as the surface charge of adsorbent [37]. The effects of the $\mathrm{pH}$ on the extraction of $\mathrm{Cu}, \mathrm{Cd}, \mathrm{Co}, \mathrm{Cr}, \mathrm{Pb}$, and $\mathrm{Zn}$ ions as an adsorbate on Gly-, IDA-, and AP-functionalized MSNs were investigated in the $\mathrm{pH}$ range of 3-9. The results are given in Figure 5. The results illustrate that at $\mathrm{pH} 9$, most of the studied metal ions were removed with removal efficiency of more than $85 \%$ and $95 \%$ when Gly-MSN and AP-MSN were used, respectively. On the other hand, the behaviour of IDA-MSN was completely different in terms of the removal of cobalt ion as there was a decrease in the extraction efficiency to $40 \%$, and that might be attributed to the formation of the hydroxyl complexes of cobalt $\mathrm{Co}(\mathrm{OH})_{2}$ at higher $\mathrm{pH}$ medium which can be hindered by the presence of dicarboxylic acid of IDA-MSN [24, 25]. In general, the removal efficiency was low at $\mathrm{pH} 3$ across all samples towards the studied ions. However, there was a slight variation in the adsorption over the studied elements when AP-MSN is used. Interestingly, a completely different behaviour was observed when the surfaces were modified with Glycine and IDA; as some of the elements (Cd, Co, and $\mathrm{Zn}$ ) were meanly hindered to interact with the surface of the materials. The removal efficiency of $\mathrm{Pb}$ and $\mathrm{Cu}$ ions increased from 20 to $45 \%$ and from 10 to $30 \%$, respectively, when the number of carboxylic acid moieties increased in the functional group. This result was significant as it demonstrated the selectivity of IDA-MSN for the removal of $\mathrm{Pb}$ and $\mathrm{Cu}$ even when it was present in aqueous solution containing multielements. 


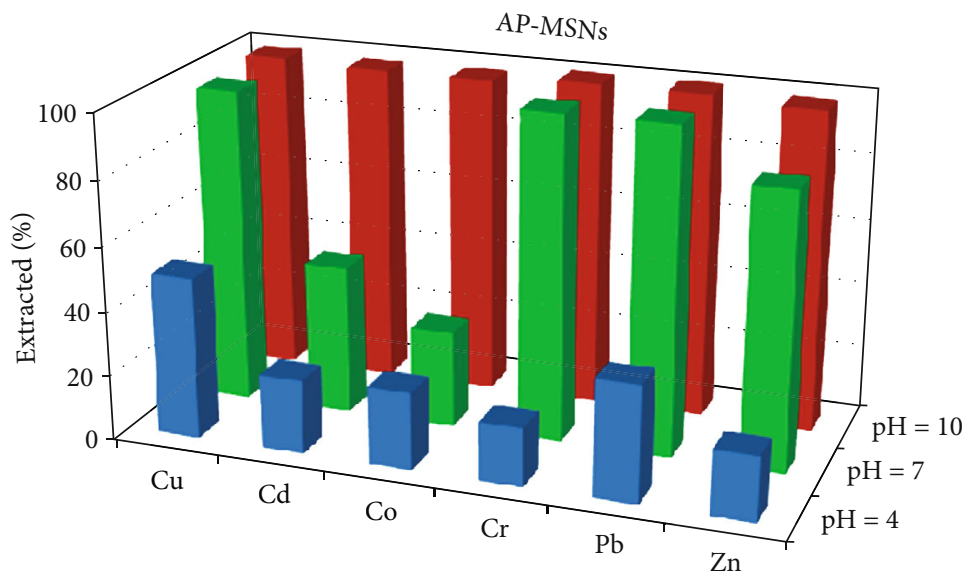

(a)

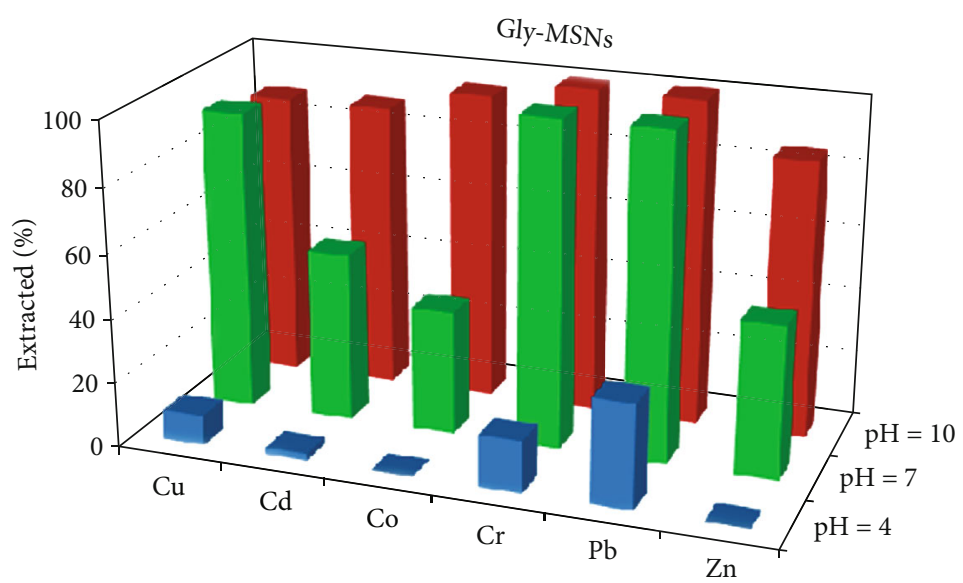

(b)

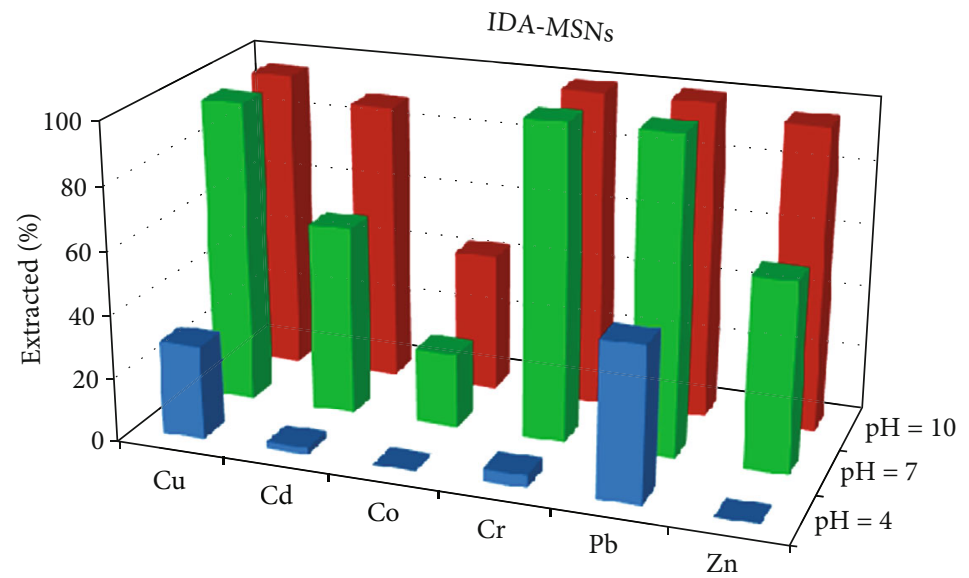

(c)

FIGURE 5: Effect of $\mathrm{pH}$ for the extraction of contaminated solution of multielement using (a) AP-MSNs, (b) Gly-MSNs, and (c) IDA-MSNs.

3.2.1. Polymeric Membranes. Water permeability of membranes was investigated that the behaviour of water permeability of the prepared membranes were differed due to variations of surface area, pore size density, different thicknesses, and network structure [38]. The permeability of water is defined as the water volume per time, which across an area of membrane at different applied pressure. Water permeability of membranes can be determined from the slope resulting from time against permeate volume as shown in Figure 6 and summarized in Table 3. The permeability of water for each membrane was calculated using equation (3): [39]

$$
J=\left(\frac{1}{A}\right) \frac{d V_{p}}{d t},
$$




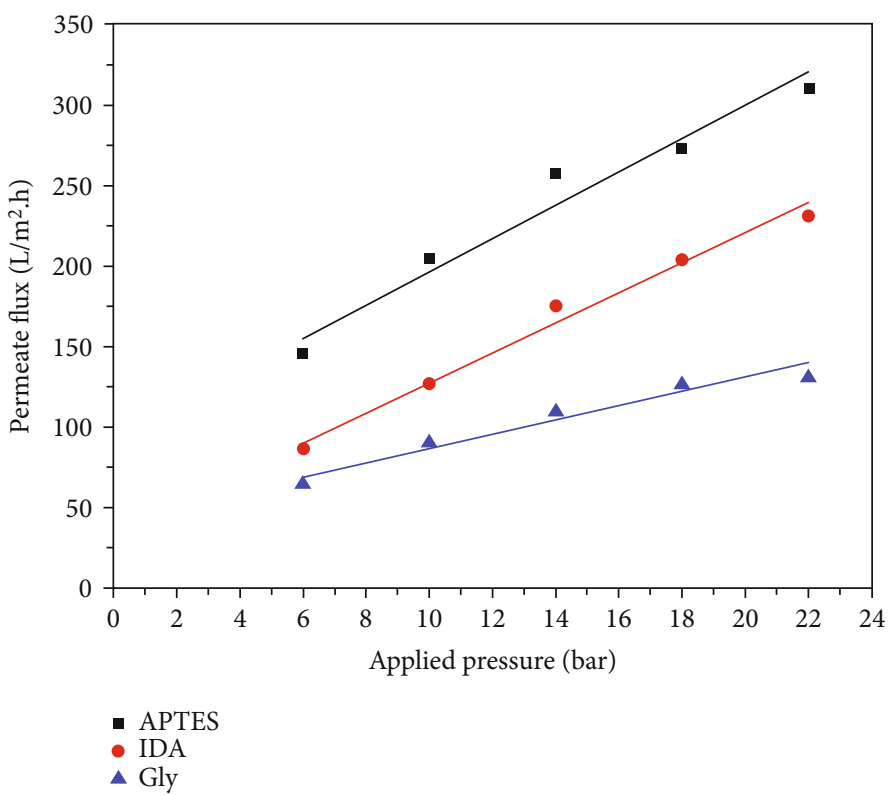

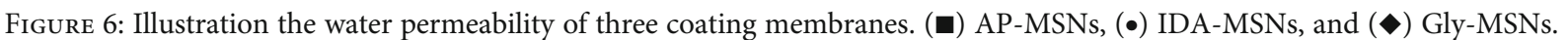

TABLE 3: Summarize the water permeability of membranes determination.

\begin{tabular}{lc}
\hline Material & Water permeability $\left(\mathrm{L} / \mathrm{m}^{2} \cdot\right.$ h.bar $)$ \\
\hline AP-MSNs & $9.96 \pm 3$ \\
Gly-MSNs & $9.15 \pm 4$ \\
IDA-MSNs & $4.24 \pm 3$ \\
\hline
\end{tabular}

where $J$ is the permeability of water, while $V_{p}$ is the permeate volume, $A$ is the efficiency membrane area, and $t$ is the time (per hour). Figure 6 shows a comparison of the water permeability of the three types of membranes and is summarized in Table 3. Figure 6 shows that the permeate flux of prepared membranes was increased linearly with increasing the applied pressure as expected. It is also demonstrated that the prepared membranes have high water permeability and appropriate mechanical properties to withstand the high pressure applied to them. Table 3 shows that the AP-MSN/chitosan coating membrane has a significantly higher water permeability $\left(9.96 \pm 3 \mathrm{~L} / \mathrm{m}^{2}\right.$.h.bar) than other membranes, which are Gly-MSNs/chitosan and IDA-MSNs/chitosan (9.15 \pm 4 and $4.24 \pm 3 \mathrm{~L} / \mathrm{m}^{2}$.h.bar, respectably). Additionally, it is noted that the water permeability values of coating membranes (AP-MSNs/chitosan, Gly-MSNs/chitosan, and IDAMSNs/chitosan) investigated here were higher than those seen previously with other nanoparticles (CNTs) [40, 41]. Consequently, results suggest that the high water permeability of prepared membranes is a result from functionalized silica nanoparticles (Gly-MSN, IDA-MSN, and AP-MSN).

3.2.2. Heavy Metals-Rejection Capability. Three coating membranes AP-MSNs/chitosan, Gly-MSNs/chitosan, and IDA-MSNs/chitosan were evaluated for the rejection of heavy metals such as $\mathrm{Cu}^{+2}, \mathrm{~Pb}^{+2}, \mathrm{Co}^{+2}, \mathrm{Cd}^{+2}$, and $\mathrm{Ni}^{+2}$ using a cross-flow system. The prepared membrane performances are shown in Figure 7. The $\mathrm{pH}$ of the solution affects the surface charge of the coating membranes and the ionization degree of heavy metals in the aqueous solution [42]. Consequently, the membrane ability to remove heavy metals from an aqueous solution can be affected by the $\mathrm{pH}$ of the solution as reported by Huang et al. [43]. The coating membranes APMSNs/chitosan, Gly-MSNs/chitosan, and IDA-MSNs/chitosan (Figure 7) show approximately similar pattern in heavy metals rejection at $\mathrm{pH} 10$ and pressure at 6 bar. The prepared membranes show high rejection range between $80 \%$ and $98 \%$ for all heavy metals. While $\mathrm{Cu}^{+2}$ and $\mathrm{Pb}^{+2}$ were great rejected by membranes with $80-95 \%$ rejection at $\mathrm{pH} 7$ with pressure at 6 bar, and $\mathrm{Cd}^{+2}, \mathrm{Co}^{+2}$, and $\mathrm{Ni}^{+2}$ were rejected with 10 $40 \%$ range at the same $\mathrm{pH}$ and pressure. Both the APMSN/chitosan and the IDA-MSNs/chitosan coating membranes showed slight variation in the heavy metal rejection, ranging between $60 \%$ and $80 \%$ at $\mathrm{pH} 4$ and 6 bar. While the Gly-MSNs/chitosan coating membrane was totally different in terms of the rejection of heavy metals as there was a decrease in the removal efficiency due to the creation of the hydroxyl complexes with the metals at lower $\mathrm{pH}$ medium.

\section{Conclusions}

We have studied a method for synthesizing mesoporous silica materials which were subjected to surface modification with three different functional groups (i.e., amine, iminodiacetic acid, and glycine) to be used as an adsorbent for heavy metals. The physiochemical characterization of the materials shows a mesoporous structure as confirmed by the BET isotherms with a surface area of $1048 \mathrm{~m}^{2} \mathrm{~g}^{-1}$ and a large pore size of ca. $6 \mathrm{~nm}$. Batch experiments were performed to study the effect of the $\mathrm{pH}$ on the presence of various metal ions (e.g., $\mathrm{Cu}, \mathrm{Cd}, \mathrm{Co}, \mathrm{Cr}, \mathrm{Pb}$, and $\mathrm{Zn}$ ions). The obtained results showed a maximum adsorption efficiency of $95 \%$ could be achieved using the three functional groups at $\mathrm{pH} 9$ for the 


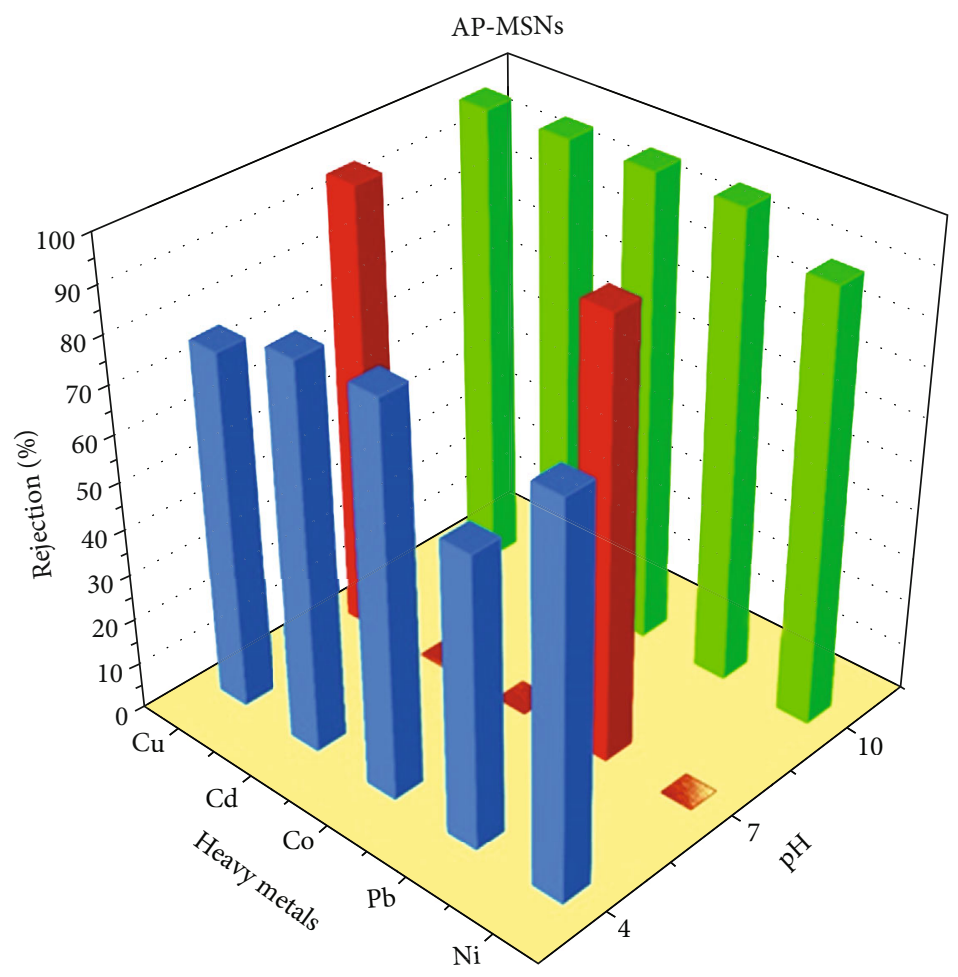

(a)

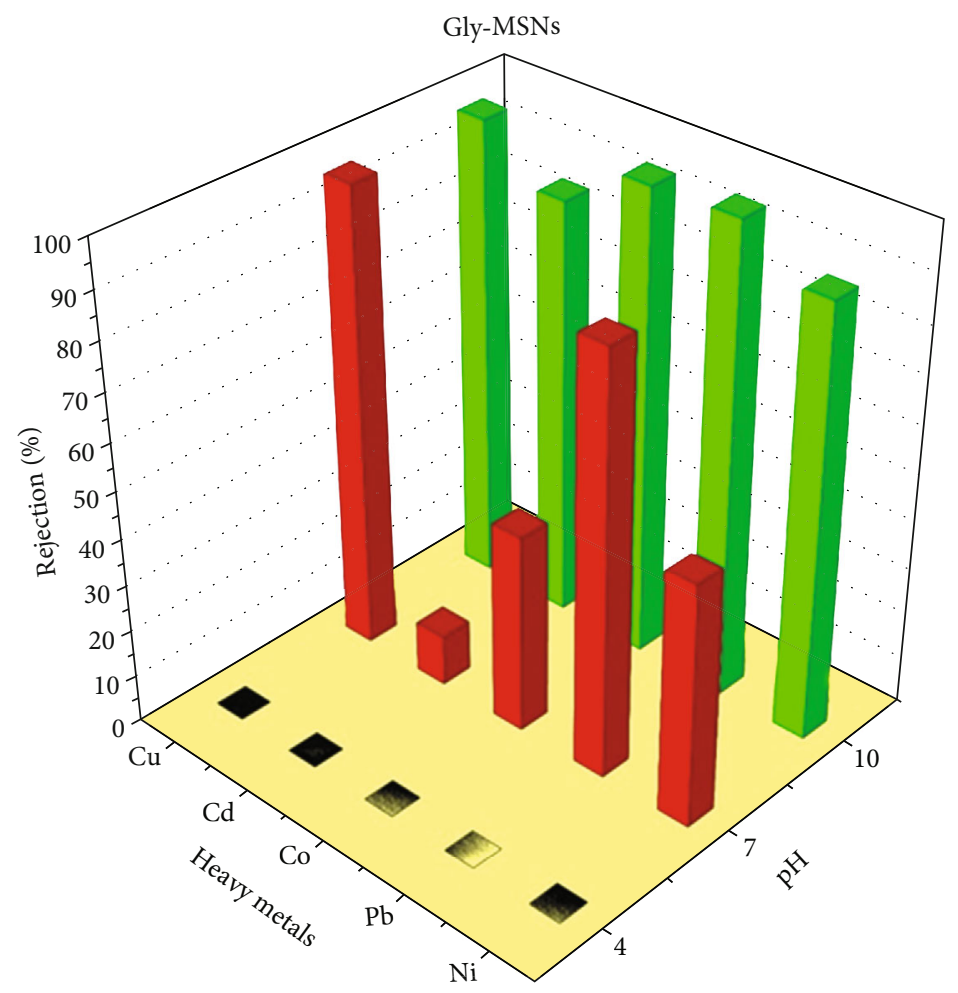

(b)

Figure 7: Continued. 


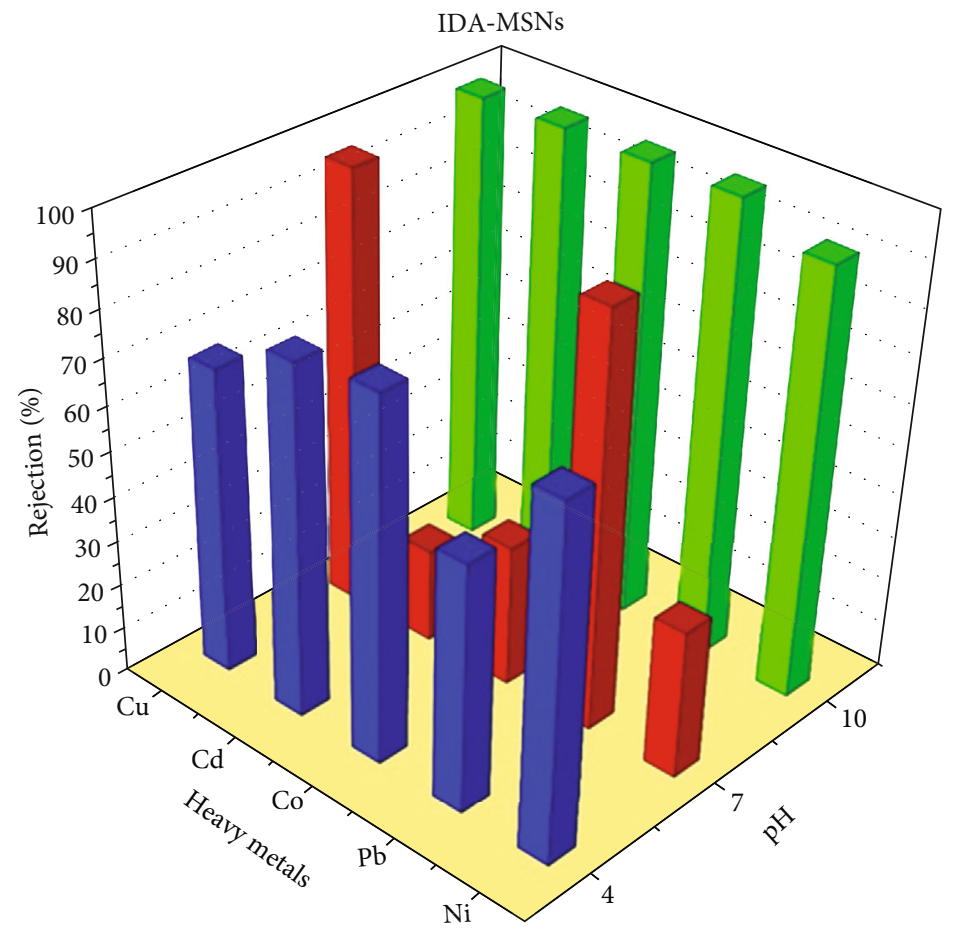

(c)

FIGURE 7: Heavy metals rejection of three coating membranes at pressure 1 bar. (a) AP-MSNs, (b) Gly-MSNs, and (c) IDA-MSNs.

studied heavy metals. Whereas, at $\mathrm{pH} 3$, the adsorption efficiency of $\mathrm{Pb}$ and $\mathrm{Cu}$ was affected by the number of carboxylic molecules present in the attached functional groups, as increasing the number of carboxylic groups had led to increasing the removal efficiency of $\mathrm{Pb}$ and $\mathrm{Cu}$ ions by two folds. Further modifications of the MSNs by using it as a support for polymeric membrane have resulted in a significantly high water permeability $\left(9.96 \pm 3 \mathrm{~L} / \mathrm{m}^{2} . \mathrm{h}\right.$.bar) compare to other coating membranes with a maximum ion rejection of $98 \%$ at $\mathrm{pH} 7$ for $\mathrm{Cu}^{+2}$ and $\mathrm{Pb}^{+2}$ ions. Finally, the developed polymeric membrane modified with silica nanoparticles has the potential to become a promising polymeric nanocomposite membrane; it could be used to produce freshwater from a contaminated water sample.

\section{Data Availability}

(1) SEM and TEM images of materials are used to support the findings that the prepared are mesoporous silica nanoparticles. (2) Table is used to support the findings that the surface area of the materials reduced die to the functionalization. (3) Nitrogen adsorption isotherms are Type 4, which are used to support the findings that the materials are mesoporous. (4) FT-IR and TGA are used to support the findings that the functional groups are successfully functionalized on the surface of the materials. (5) Demonstration of the amount of toxic metal adsorbed on the nanomaterials at different $\mathrm{pH}$ to support the findings that the adsorption capacity is affected by different functional groups.

\section{Conflicts of Interest}

The authors declare that they have no conflicts of interest.

\section{Authors' Contributions}

Abdullah M Alswieleh and Khalid M Alotaibi contributed equally to this work.

\section{Acknowledgments}

The authors extend their appreciation to the Deanship of Scientific Research at King Saud University for funding this work through research group no.RG-1441-304.

\section{References}

[1] United Nations World Water Assessment Programme (UN WWAP), "UN World Water Development Report, Naturebased Solutions for Water," 2018, http://www.unesco.org/ new/en/natural-sciences/environment/water/wwap/wwdr/ 2018-nature-based-solutions/.

[2] D. Vilela, J. Parmar, Y. Zeng, Y. Zhao, and S. Sánchez, "Graphene-based microbots for toxic heavy metal removal and recovery from water," Nano Letters, vol. 16, no. 4, pp. 2860-2866, 2016.

[3] F. Almomani, R. Bhosale, M. Khraisheh, and T. Almomani, "Heavy metal ions removal from industrial wastewater using magnetic nanoparticles (MNP)," Applied Surface Science, vol. 506, p. 144924, 2020.

[4] M. A. Al-Anber, Z. A. Al-Anber, I. Al-Momani, F. AlMomani, and Q. Abu-Salem, "The performance of defatted jojoba seeds for the removal of toxic high concentration of 
the aqueous ferric ion," Desalination and Water Treatment, vol. 52, no. 1-3, pp. 293-304, 2013.

[5] K. F. Lam, K. L. Yeung, and G. McKay, "A rational approach in the design of selective mesoporous adsorbents," Langmuir, vol. 22, no. 23, pp. 9632-9641, 2006.

[6] D. Pérez-Quintanilla, I. del Hierro, M. Fajardo, and I. Sierra, "Adsorption of cadmium (II) from aqueous media onto a mesoporous silica chemically modified with 2-mercaptopyrimidine," Journal of Materials Chemistry, vol. 16, no. 18, pp. 1757-1764, 2006.

[7] M. H. Lim and A. Stein, "Comparative studies of grafting and direct syntheses of inorganic- organic hybrid mesoporous materials," Chemistry of Materials, vol. 11, no. 11, pp. 32853295, 1999.

[8] P. Bilalis, L.-A. Tziveleka, S. Varlas, and H. Iatrou, "pH-Sensitive nanogates based on poly (L-histidine) for controlled drug release from mesoporous silica nanoparticles," Polymer Chemistry, vol. 7, no. 7, pp. 1475-1485, 2016.

[9] H. Zhou, H. Sasabe, and I. Honma, "Synthesis of phthalocyanine-doped silica mesostructured materials by ferrocenyl surfactant," Journal of Materials Chemistry, vol. 8, no. 3, pp. 515-516, 1998.

[10] K. Fujiwara, H. Suematsu, E. Kiyomiya, M. Aoki, M. Sato, and N. Moritoki, "Size-dependent toxicity of silica nano-particles to Chlorella kessleri," Journal of Environmental Science and Health, Part A, vol. 43, no. 10, pp. 1167-1173, 2008.

[11] I.-Y. Kim, E. Joachim, H. Choi, and K. Kim, "Toxicity of silica nanoparticles depends on size, dose, and cell type," Nanomedicine: Nanotechnology, Biology and Medicine, vol. 11, no. 6, pp. 1407-1416, 2015.

[12] H. Yamada, C. Urata, Y. Aoyama, S. Osada, Y. Yamauchi, and K. Kuroda, "Preparation of colloidal mesoporous silica nanoparticles with different diameters and their unique degradation behavior in static aqueous systems," Chemistry of Materials, vol. 24, no. 8, pp. 1462-1471, 2012.

[13] S.-H. Wu, C.-Y. Mou, and H.-P. Lin, "Synthesis of mesoporous silica nanoparticles," Chemical Society Reviews, vol. 42, no. 9, pp. 3862-3875, 2013.

[14] P. Stathi, K. Dimos, M. A. Karakassides, and Y. Deligiannakis, "Mechanism of heavy metal uptake by a hybrid MCM-41 material: surface complexation and EPR spectroscopic study," Journal of Colloid and Interface Science, vol. 343, no. 1, pp. 374-380, 2010.

[15] X. Wang, Y. Zhang, W. Luo et al., "Synthesis of ordered mesoporous silica with tunable morphologies and pore sizes via a nonpolar solvent-assisted stober method," Chemistry of Materials, vol. 28, no. 7, pp. 2356-2362, 2016.

[16] E. F. S. Vieira, J. Simonide, and C. Airoldi, "Interaction of cations with SH-modified silica gel: thermochemical study through calorimetric titration and direct extent of reaction determination," Journal of Materials Chemistry, vol. 7, no. 11, pp. 2249-2252, 1997.

[17] U. Wingenfelder, B. Nowack, G. Furrer, and R. Schulin, "Adsorption of $\mathrm{Pb}$ and $\mathrm{Cd}$ by amine-modified zeolite," Water Research, vol. 39, no. 14, pp. 3287-3297, 2005.

[18] L. Bulgariu and D. Bulgariu, "Functionalized soy waste biomass-a novel environmental-friendly biosorbent for the removal of heavy metals from aqueous solution," Journal of Cleaner Production, vol. 197, pp. 875-885, 2018.

[19] P. Stathi, K. Litina, D. Gournis, T. S. Giannopoulos, and Y. Deligiannakis, "Physicochemical study of novel organoclays as heavy metal ion adsorbents for environmental remediation," Journal of Colloid and Interface Science, vol. 316, no. 2, pp. 298-309, 2007.

[20] S. A. Idris, K. M. Alotaibi, T. A. Peshkur, P. Anderson, M. Morris, and L. T. Gibson, "Adsorption kinetic study: effect of adsorbent pore size distribution on the rate of $\mathrm{Cr}$ (VI) uptake," Microporous and Mesoporous Materials, vol. 165, pp. 99-105, 2013.

[21] S. A. Idris, K. Alotaibi, T. A. Peshkur, P. Anderson, and L. T. Gibson, "Preconcentration and selective extraction of chromium species in water samples using amino modified mesoporous silica," Journal of Colloid and Interface Science, vol. 386, no. 1, pp. 344-349, 2012.

[22] R. Gupta, S. K. Gupta, and D. D. Pathak, "Selective adsorption of toxic heavy metal ions using guanine-functionalized mesoporous silica [SBA-16-g] from aqueous solution," Microporous and Mesoporous Materials, vol. 288, p. 109577, 2019.

[23] M. Wang, X. Ren, L. Zhu, Y. Xia, and J. Qiu, "Preparation of mesoporous silica/carbon quantum dots composite and its application in selective and sensitive $\mathrm{Hg}^{2+}$ detection," Microporous and Mesoporous Materials, vol. 284, pp. 378384, 2019.

[24] A. M. Alswieleh, M. M. Alshahrani, K. E. Alzahrani et al., "Surface modification of $\mathrm{pH}$-responsive poly (2-(tert-butylamino) ethyl methacrylate) brushes grafted on mesoporous silica nanoparticles," Designed Monomers and Polymers, vol. 22, no. 1, pp. 226-235, 2019.

[25] W. Kaewprachum, S. Wongsakulphasatch, W. Kiatkittipong, A. Striolo, C. K. Cheng, and S. Assabumrungrat, "SDS modified mesoporous silica MCM-41 for the adsorption of $\mathrm{Cu}^{2+}$, $\mathrm{Cd}^{2+}, \mathrm{Zn}^{2+}$ from aqueous systems," Journal of Environmental Chemical Engineering, vol. 8, no. 1, p. 102920, 2020.

[26] J. I. Lachowicz, G. R. Delpiano, D. Zanda et al., "Adsorption of $\mathrm{Cu}^{2+}$ and $\mathrm{Zn}^{2+}$ on SBA-15 mesoporous silica functionalized with triethylenetetramine chelating agent," Journal of Environmental Chemical Engineering, vol. 7, no. 4, p. 103205, 2019.

[27] J. Wang, X. Tong, Y. Chen, T. Sun, L. Liang, and C. Wang, "Enhanced removal of Cr (III) in high salt organic wastewater by EDTA modified magnetic mesoporous silica," Microporous and Mesoporous Materials, vol. 110262, 2020.

[28] G.-d. Kang and Y.-m. Cao, "Development of antifouling reverse osmosis membranes for water treatment: a review," Water Research, vol. 46, no. 3, pp. 584-600, 2012.

[29] S. G. Kim, D. H. Hyeon, J. H. Chun, B.-H. Chun, and S. H. Kim, "Nanocomposite poly (arylene ether sulfone) reverse osmosis membrane containing functional zeolite nanoparticles for seawater desalination," Journal of Membrane Science, vol. 443, pp. 10-18, 2013.

[30] H. Zhao, S. Qiu, L. Wu, L. Zhang, H. Chen, and C. Gao, "Improving the performance of polyamide reverse osmosis membrane by incorporation of modified multi-walled carbon nanotubes," Journal of Membrane Science, vol. 450, pp. 249256, 2014.

[31] B.-H. Jeong, E. M. Hoek, Y. Yan et al., "Interfacial polymerization of thin film nanocomposites: a new concept for reverse osmosis membranes," Journal of Membrane Science, vol. 294, no. 1-2, pp. 1-7, 2007.

[32] G. L. Jadav and P. S. Singh, "Synthesis of novel silicapolyamide nanocomposite membrane with enhanced properties," Journal of Membrane Science, vol. 328, no. 1-2, pp. 257-267, 2009. 
[33] P. Shah and C. Murthy, "Studies on the porosity control of MWCNT/polysulfone composite membrane and its effect on metal removal," Journal of Membrane Science, vol. 437, pp. 90-98, 2013.

[34] W.-P. Zhu, J. Gao, S.-P. Sun, S. Zhang, and T.-S. Chung, "Poly (amidoamine) dendrimer (PAMAM) grafted on thin film composite (TFC) nanofiltration (NF) hollow fiber membranes for heavy metal removal," Journal of Membrane Science, vol. 487, pp. 117-126, 2015.

[35] Y. Zhang, S. Zhang, J. Gao, and T.-S. Chung, "Layer-by-layer construction of graphene oxide (GO) framework composite membranes for highly efficient heavy metal removal," Journal of Membrane Science, vol. 515, pp. 230-237, 2016.

[36] A. M. Alswieleh, A. M. Beagan, B. M. Alsheheri, K. M. Alotaibi, M. D. Alharthi, and M. S. Almeataq, "Hybrid mesoporous silica nanoparticles grafted with 2-(tert-butylamino) ethyl methacrylate-b-poly (ethylene glycol) methyl ether methacrylate diblock brushes as drug nanocarrier," Molecules, vol. 25, no. 1, p. 195, 2020.

[37] M. A. A. Ragab, M. A. Korany, H. Z. Ibrahim, M. A. AbdelKawi, and A. E. A. A. A. Sayed, "Adsorption behavior of some metal ions on nanoparticles used in pharmaceutical matrices: application to laboratory made drug formulation," Bulletin of Faculty of Pharmacy, Cairo University, vol. 55, no. 1, pp. 155-162, 2017.

[38] C. Clasen, T. Wilhelms, and W.-M. Kulicke, "Formation and characterization of chitosan membranes," Biomacromolecules, vol. 7, no. 11, pp. 3210-3222, 2006.

[39] M. Zargar, Y. Hartanto, B. Jin, and S. Dai, "Polyethylenimine modified silica nanoparticles enhance interfacial interactions and desalination performance of thin film nanocomposite membranes," Journal of Membrane Science, vol. 541, pp. 1928, 2017.

[40] A. A. Alshahrani, M. S. Algamdi, I. H. Alsohaimi et al., "The rejection of mono-and-di valent ions from aquatic environment by MWNT/Chitosan buckypaper Composite membranes: influences of chitosan concentrations," Separation and Purification Technology, vol. 234, p. 116088, 2019.

[41] A. A. Alshahrani, H. Al-Zoubi, and L. D. Nghiem, "Synthesis and characterisation of MWNT/chitosan and MWNT/chitosan-crosslinked buckypaper membranes for desalination," Desalination, vol. 418, pp. 60-70, 2017.

[42] A. Albert, "Ionization, $\mathrm{pH}$ and biological activity," Pharmacological Reviews, vol. 4, no. 2, pp. 136-167, 1952.

[43] Y. Huang, X. Lee, F. C. Macazo, M. Grattieri, R. Cai, and S. D. Minteer, "Fast and efficient removal of chromium (VI) anionic species by a reusable chitosan-modified multi-walled carbon nanotube composite," Chemical Engineering Journal, vol. 339, pp. 259-267, 2018. 